\title{
Recurrent miscarriage
}

\author{
Patience and possibly lower concentrations of luteinising hormone before \\ conception are needed
}

Recurrent miscarriage (the loss of three or more consecutive pregnancies before 20 weeks' gestation') presents the patient and her doctor with a dilemma. Are patients suffering from a distinct clinical disorder or have they been victims of chance? If the former then a single cause is unlikely as the clinical presentation is so variable, ranging from early occult failures of implantation to overt miscarriages in the first and second trimesters of pregnancy. Even after careful investigation only rarely can a cause be identified, meaning that treatment is usually empirical. Results of such treatment regimens are necessarily inconclusive.

The precise incidence of recurrent miscarriage is unknown. If miscarriage always occurred randomly and as $15 \%$ of all clinically recognised pregnancies miscarry² then we would expect $0.4 \%$ of women to miscarry three consecutive pregnancies. ${ }^{3}$ Observed frequencies, however, are higher $(0.8 \%$ $1 \cdot 0 \%$, suggesting that specific causes of this type of reproductive failure may exist. ${ }^{+}$The chance of a successful pregnancy after three previous miscarriages is about $60 \%$ - high enough for some clinicians to question whether any treatment is justified. Understandably, patients do not share this opinion.

The results of a recent study of early pregnancy loss suggest that the single most important predictive factor for miscarriage is having previously miscarried. ${ }^{5}$ Primigravidas and women with a history of successful pregnancies miscarry infrequently: for unknown reasons, the outcome of a woman's first pregnancy seems to affect her future reproductive performance. Although fetal chromosome abnormalities are the main cause of sporadic miscarriage, patients with repeated losses tend to miscarry fetuses that are chromosomally normal, and balanced parental translocations occur in no more than one in 20 couples. ${ }^{.}$Structural abnormalities of the genital tract rarely cause miscarriage, hardly justifying their surgical repair. The interim report from the Medical Research Council multicentre trial of cervical cerclage suggests that this treatment does not significantly improve pregnancy outcome. ${ }^{x}$ Infection," diabetes mellitus, and thyroid disease are rarely present.

Considerable attention has been paid to the possibility of immunologically mediated miscarriage. In systemic lupus erythematosus, successful pregnancies follow treatment with low dose aspirin, systemic steroids, and heparin, probably because the extent of placental thrombotic episodes and infarction has been reduced. "' Furthermore, fetal loss may occur at any gestation in women who develop antiphospholipid antibodies (anticardiolipin and lupus anticoagulant)." The possibility that some women miscarry recurrently because of an alloimmune aberration, which prevents them from mounting a protective response towards their genetically dissimilar conceptus, has also been explored. There is evidence that the placenta (the feto-maternal interface) contributes to its own survival by being relatively immunologically inertclassic major histocompatibility antigens are absent from the trophoblast cells of chorionic villi. ${ }^{12}$

Opinion has, however, swung towards the view that maternal recognition of trophoblast antigens might, paradoxically, be beneficial to pregnancy, perhaps by producing "blocking" antibodies, although what is being blocked is unclear..$^{13+}$ Based on this hypothesis, many centres have begun immunising women for recurrent miscarriage, aiming at inducing this putative response. Trophoblast, paternal, and unrelated lymphocytes have all been used as immunogens, ${ }^{15} 16$ but so far only one randomised controlled trial has shown any benefit. ${ }^{16}$

The local interaction between migrating extravillous trophoblast and leucocytes infiltrating the uterus is currently being studied. These leucocytes are composed mainly of large granular lymphocytes with natural killer cell activity. Their numbers increase during the first half of the menstrual cycle, reaching a peak in the late secretory phase. If pregnancy occurs then the concentrations are maintained into the decidua. ${ }^{17}$ The proliferation of these large granular lymphocytes in the endometrium around the time of implantation suggests that they may have a role in establishing pregnancy, particularly since the trophoblast is resistant to lysis by decidual natural killer cells. ${ }^{18}$

Endocrinological explanations of recurrent miscarriage have always been attractive, with most studies concentrating on events that follow ovulation and conception. Although progesterone concentration has been found to be low in the luteal phase and early pregnancy in these patients, attempts to improve the efficiency of the corpus luteum with exogenous hormones (such as human chorionic gonadotrophin and progesterone) have not helped. ${ }^{19}$ Advances in assisted fertility treatment have shown that successful implantation and continuation of pregnancy depend partly on what happens in the first half of the menstrual cycle. In particular, high concentrations of luteinising hormone during the period of 
oocyte development have been found to correlate with a poor outcome. ${ }^{20 \cdot 22}$

Once again an explanation is lacking, although the association may be secondary to the polycystic ovary syndrome, which is present in $23 \%$ of all women and in some $80 \%$ of patients with recurrent miscarriage (diagnosed with ultrasonography). ${ }^{23}$ Alternatively, it may be explained by the effect of luteinising hormone on the production of ovarian steroids or on the maturation of oocytes. ${ }^{24}$ Whichever it is, knowing that a raised concentration of serum luteinising hormone increases the risk of miscarriage provides us with a predictive test for women before pregnancy. An abnormal result may identify a subgroup of patients with a potentially remediable cause for their pregnancy losses: hypersecretion of luteinising hormone, which may be suppressed by gonadotrophic releasing agonists, ${ }^{25} 26$ ovarian diathermy, ${ }^{27}$ and somatostatin. ${ }^{28}$

Clinicians must remember that women who have miscarried recurrently from one cause are not protected from a further miscarriage from another cause. Most importantly, when assessing the efficacy of treatment for patients with recurrent miscarriage we must remember that even without treatment about $60 \%$ of these women will be successful in their next pregnancy.

Senior Lecturer in Obstetrics and Gynaecology,

LESLEY REGAN

St Mary's Hospital,

London W2 IPG

1 World Health Organisation. Recommended definitions, terminology and format for statistica tables related to the perinatal period. Acta Obstet Gynecol Scand 1977;56:247-53.

2 Warburton D, Fraser FC. Spontaneous abortion risks in man: data from reproductive histories collected in a medical genetics unit. Human Genet 1964;16:1-25.

3 Huisies HJ. Spontaneous abortion. Edinburgh: Churchill Livingstone, 1984.

4 Alberman E. The epidemiology of repeated abortion. In: Beard RW, Sharp F, eds. Early pregnancy

loss: mechanisms and treatment. London: Royal College of Obstetricians and Gynaecologists, 1988:9-17.
5 Regan L, Braude PR, Trembath PL. Influence of past reproductive performance on risk of spontancous abortion. BMF 1989;299:541-5.

6 Warburton D, Strobino B. Recurrent spontaneous abortion. In: Bennet MJ, Edmonds DK, cds Spontaneous and recurrent abortion. Oxford: Blackwell Scientific, 1987: 193-213

7 Bennett MJ. Congenital abnormalities of the fundus. In: Bennett MJ, Edmonds DK, eds. Spontuneous and recurrent abortion. Oxford: Blackwell Scientific, 1987:109-29.

8 Medical Research Council and Royal College of Obstetricians and Gynaecologists W/orking Party on Cervical Cerclage. Interim report. Br f Obstet (Gynaecol 1988;95:437-45.

9 Watts DH, Eschenbach DA. Reproductive tract infections as a cause of abortion and preterm birth. Seminars in Reproductive Endocrinology 1988;6:203-15

10 Lubbe WF, Liggins GC. Role of lupus anticoagulant and pregnancy. Seminars in Reproductive Endocrinology 1988;6:181-90.

11 Derue GJ, Englert HJ, Harris EN, et al. Fetal loss in systemic lupus erythematosus: asseciation with anti-cardiolipin antibodies. Am f Obstet Gynecol 1985;5:207-9.

12 Fault WP, Temple A. Distribution of beta-2 microglobulin and HLA in chorionic villi of human placentae. Nature 1976;262:799-802.

3 McIntyre JA, Faulk WP. Trophoblast modulation of maternal allogeneic recognition. Proc Natl Acad Sci USA 1979;76:4029-32.

14 McIntyre JA. In search of trophoblast-lymphocyte cross-reactive (TLX) antigens. American foumal of Reproductive Immunology and Microbiology 1988;17:100-10.

15 Johnson PM, Chia KV, Hart CA, Griffith HB, Francis WJA. Trophoblast membrane infusion for unexplained recurrent miscarriage. Br f Obstet Gynaecol 1988;95:342-7.

16 Mowbray JF, Gibhings $C$, Liddell H, Reginald PW, Underwood JL, Beard RW Controlled trial of treatment of recurrent miscarriage with paternal cells. Lancet 1984;i:941-3.

17 King A, Wellings V, Gardner I, Loke YW. Immunocytochemical characterisation of the unusual large granular lymphocytes in human endometrium throughout the menstrual cycle. Hum Immunol 1989;24:195-205

18 King A, Birkby C, Loke YW. Early human decidual cells exhibit NK activity against the K562 cell line but not against first trimester trophoblast. Cell Immunol 1989;121:166-73.

19 Reijnders F, Thomas CMG, Doesburg WH, Rolland J, Eskes TK. Endocrine effects of 17 alpha hydroxyprogesterone caproate during early pregnancy: a double blind clinical trial. $\mathrm{Br} \mathcal{C}$ Obste Gynaecol 1988;95:262-8.

20 Stanger JD, Yovich JL. Reduced in-vitro fertilisation of human oocytes from patients with raised basal LH levels during the follicular phase. Br $\mathcal{O}$ Obstet Gynaecol 1985;92:385-93.

21 Punnonen R, Heinonen PK, Ashorn R, Kujansuu E, Vilja P, Tuohimaa P. Spontaneous luteinising hormone surge and cleavage of in vitro fertilised embryos. Fertil Steril 1988;49:479-82.

22 Regan L, Owen EJ, Jacobs HS. Hypersecretion of luteinising hormone, infertility and miscarriage. Lancel 1990;336:1141-4.

23 Sagle $M$, Bishop K, Ridley $N$, et al. Recurrent early miscarriage and polycystic ovaries. $B M 7$ 1988;297:1027-8.

24 Jacobs HS, Homburg RR. The endocrinology of conception. Ballieres Clin Endocrinol Metab 1990;4:195-205.

25 Johnson P, Pearce JM. Recurrent spontaneous abortion and polycystic ovary disease: comparison of two regimens to induce ovulation. BMF 1990;300:154-6.

26 Homburg R, Eshel A, Kilborn J, Adams J, Jacobs HS. Combined luteinising hormone releasing hormone analogue and exogenous gonadotrophins for the treatment of infertility associated with polycystic ovaries. Hum Reprod 1990;5:32-5.

27 Armar NA, MacGarrigle HHG, Honour JW, Holownia P, Jacobs HS, Lachelin GCL. Laparoscopic ovarian diathermy in the management of anovulatory infertility in women with polycystic ovaries: endocrine changes and clinical outcome. Fertil Steril 1990;53:45-9.

28 Prelevic GM, Wurzburger MI, Balint-Peric L, Nesic JS. Inhibitory effect of sandostatin on secretion of luteinising hormone and ovarian steroids in polycystic ovary syndrome. Lancet 1990;336:900-3.

\section{Oral lichen planus}

\section{Not rare-and not easily treated}

The false idea that lichen planus is rare goes back to 1869 , when Erasmus Wilson presented the condition to the medical world'-just a few years before he presented Cleopatra's needle to London. The notion has stuck for two main reasons. Firstly, many people with lichen planus, particularly when it is confined to the mouth, have no idea that there is anything wrong with them. Secondly, some doctors find it hard to recognise lichen planus -in one study of primary care physicians fewer than one in five could do so. ${ }^{2}$

The truth emerges only when large populations are examined by experts. Even so, some dermatologists were astonished to read that lichen planus had been found in. $14 \%$ of 20749 Americans aged under 75 , thought to be representative of the general population. ${ }^{3}$ Admittedly only one in 100 of these people had lichen planus badly enough to need medical attention, but the numbers seemed unexpectedly large.

The prevalence of oral lichen planus is now known for several countries and runs at about $1 \%$ or $2 \% .^{+}$In the cases found in such studies there are seldom lesions on the skin as well as in the mouth. These patients may show the classical lacework of fine white lines and papules inside their cheeks, but their symptoms are few and they need no treatment.

In contrast are the patients who attend dental clinics with pain and burning arising from atrophic areas, erosions, and ulcers. For them the future seems bleak, and their symptoms are likely to persist: in one series of 611 patients only $17 \%$ of cases cleared completely over a mean observation period of seven and a half years. ${ }^{5}$ These patients have an increased risk of developing oral squamous cell carcinoma ${ }^{6}$ and perhaps psychiatric disturbances. ${ }^{7}$ What can be done to help them?

Firstly, bear in mind the possibility of a lichenoid drug reaction: stopping non-steroidal anti-inflammatory agents may be particularly helpful. ${ }^{8}$ Next, consider lichenoid reactions to dental materials, especially if the lesions lie near to old amalgam fillings. If patch testing shows mercury allergy changing to another type of filling may be worth while. . $^{-11}$ Rough fillings should be smoothed and oral hygiene improved, ${ }^{12}$ but giving up smoking makes little difference. ${ }^{13}$

Beyond this the treatments most in vogue now are corticosteroids, retinoids, and cyclosporin, used topically rather than systemically if possible. Triamcinolone can be injected into lesions, applied in Orabase (which sticks for a short while to the mucosa), or bonded to the molars in slow release preparations..$^{1+}$ Mouths affected by lichen planus carry no greater risk of excessive absorption of topical corticosteroids than normal ones. ${ }^{15}$ Isotretinoin is effective used as a gel, but the condition tends to relapse quickly when treatment is stopped. ${ }^{16}$ Most recently, in a double blind trial a topical 